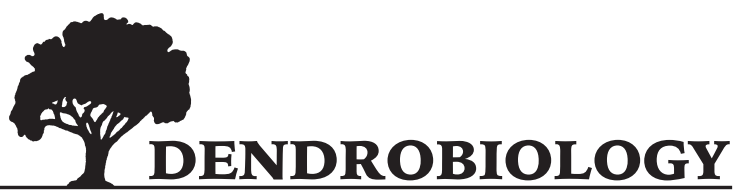

2013, vol. 70, 3-12

http://dx.doi.org/10.12657/denbio.070.001

\author{
Sudipta Shekhar Das Bhowmik, Tsering Stobdan, Lingaraj Sahoo
}

\section{Germination and short-term storage of Hippophae rhamnoides L. seeds and its ex-situ reintroduction potential assessment under North East Indian conditions}

Received: 13 July 2012; Accepted 19 November 2012

\begin{abstract}
Germination efficiency of freshly harvested Hippophae rhamnoides seeds collected from cold desert of Ladakh outside its native place under in vivo glass house condition recorded a highest of $73 \%$ germination in soilrite at $22 \pm 2^{\circ} \mathrm{C}$ and $60-70 \% \mathrm{RH}$ within three weeks at Guwahati, North East India. Germination of seeds was significantly enhanced to a maximum of $90 \%$ under in vitro condition in $1 / 4^{\text {th }}$ Murashige \& Skoog (MS) medium supplemented with $3 \%$ sucrose and $2 \%$ activated charcoal within two weeks. Glass house acclimatized healthy seedlings after been introduced to natural climatic conditions of Shillong and Guwahati of North East India showed inadequate survivability. Unlike storage at room temperature which is detrimental for seed viability, low temperature storage under refrigeration and natural climatic condition of Ladakh retains viability for prolonged period.
\end{abstract}

Additional key words: in vitro, in vivo, polyphenols, viability, introduction, substratum

Addresses: S.S.D. Bhowmik, L. Sahoo, Department of Biotechnology, Indian Institute of Technology, Guwahati - 781039, India, e-mail: sudiptashekhar@rediffmail.com

T. Stobdan, Defence Institute of High Altitude Research, Leh-Ladakh - 194 101, India

\section{Introduction}

Hippophae rhamnoides L. commonly known as Seabuckthorn is a medicinal shrub predominantly found in temperate Himalayan regions in the cold desert of Ladakh and can withstand temperature from -43 to $40^{\circ} \mathrm{C}$ ( $\mathrm{Lu} \mathrm{1992;} \mathrm{Yao} \mathrm{1994).} \mathrm{There} \mathrm{are} \mathrm{four}$ Hippophae species namely, $H$. rhamnoides, $H$. salicifolia, $H$. tibetana, and $H$. gyantsensis that represent the genus in India (Naithani 2004). Ladakh hosts H. rhamnoides and H. salicifolia (Ali and Kaul 2011) whereas H. salicifolia has been reported in Sikkim and Arunachal Pradesh of North East India (Naithani 2004; Raina et al. 2012). Plant of Hippophae species are dioecious with separate male and female characteristics. The fruit of $H$. rhamnoides commercially known as novel 'super-fruit are rich source of complex vitamins (A, B, $\mathrm{C}, \mathrm{D}, \mathrm{E}, \mathrm{F}, \mathrm{K}$ and $\mathrm{P}$ ); mineral (Na, K, Ca); carbohydrates, proteins, amino acids, tannins; triterpenoids, phospholipids, caumarin, catechins, leucoenthocyans, flavonols, alkaloids, serotonin as well as omega 3 and one 7 unsaturated fatty acids (Kalia et al. 2011; Kanayama et al. 2012). Concentration of vitamins $B_{2}$, $\mathrm{B}_{3}, \mathrm{~B}_{5}, \mathrm{~B}_{6}, \mathrm{~B}_{12}, \mathrm{C}$ and $\mathrm{E}$ is much higher than other fruits such as apricot, banana, mango, orange and peach (Stobdan et al. 2010). Seabuckthorn pulp, seeds, leaves and stem bark contain high levels of phenolic content and antioxidants (Korekar et al. 2011). The 
plant is commonly used as a remedial of gastric, thrombosis, hepatic and ligament injuries, reducing cholesterol level and cancer (Stobdan et al. 2008). Besides medicinal uses the plant has been regularly used for soil and water conservation, desertification control, land reclamation in fragile cold desert ecosystem due to their natural potentialities to symbiotically fix atmospheric nitrogen with actinomycetes mainly Frankia species to promotes effective growth in marginal soil (Akkermans et al. 1983; Zhang 2000; Tylkowski 2010). In nature, plant generally propagates through seeds and is the only means to inhabit new area (Lisenkov et al. 1969; Leme 1976). Seeds of $H$. rhamnoides form the store house of several crucial uncharacterized functional genes that encodes for its medicinal and cold tolerant properties. Germination of seed in plants is an essential phenomenon as the germination frequency varies from species to species and depends upon several biotic (genotype, metabolic activities, moisture content, plant animal interaction etc) and abiotic factors (light intensity, temperature, humidity, growth regulators, soil conditions etc). Seed germination in Hippophae sp. is also inhibited by several biotic factors such as hard coat and embryo dormancy (Landis et al. 1996; Sankhyan et al. 2005; Airi et al. 2009; Frochot et al. 2009).

To achieve higher productivity and select suitable genotypes for future breeding programmes, seed testing is very important (Mamo et al. 2006). Seeds also form the source and end material for genetic manipulation of plants. Efficiency of seed germination of $H$. salicifolia has been reported currently (Sankhyan et al. 2005; Airi et al. 2009). However, the literature cited in recent years does not deal with any comprehensive report on in vitro seed germination and storage of $H$. rhamnoides. Since North East India is one of the mega hot-spot regions of the world with diverse climatic conditions, introduction of $H$. rhamnoides that is reported to grow at different climatic condition would be very significant. Moreover, in view of the economic importance of the species assessment for possibilities of ex situ introduction at diverse geographic locations of North East India would be a great boon in future. The objective of the present study is to analyse the short-term storage and germination potentialities of $H$. rhamnoides seeds under in vivo and in vitro conditions and assess the acclimatization response of the species in North East India.

\section{Materials and methods}

\section{Collection of seeds}

The berries of $H$. rhamnoides enclosing seeds were collected from Shey area of Ladakh (31 $44^{\prime} 57^{\prime}$ $32^{\circ} 59^{\prime} 57^{\prime} \mathrm{N} 76^{\circ} 46^{\prime} 29^{\prime}-78^{\circ} 41^{\prime} \mathrm{E}$; $3524 \mathrm{~m}$ amsl), India during late September of 2010. Pulps from the berries were removed and seeds were sun dried $\left(28-30^{\circ} \mathrm{C}\right)$ for 2-3 days to prevent fungal infection. The seeds were stored in refrigerator $\left(4^{\circ} \mathrm{C}\right)$ and closed container at room temperature $\left(28-35^{\circ} \mathrm{C}\right)$ of Indian Institute of Technology, Amingaon, Guwahati, Assam, (2611'5" $\mathrm{N} ; 91^{\circ} 40^{\prime} 9{ }^{\prime \prime} \mathrm{E} ; 31 \mathrm{~m}$ amsl) and $\left(-30-30^{\circ} \mathrm{C}\right)$ of Defence Institute of High Altitude Research, Leh-Laddakh $\left(31^{\circ} 44^{\prime} 57^{\prime}-32^{\circ} 59^{\prime} 57^{\prime} \mathrm{N}\right.$; 76² $46^{\prime} 29^{\prime}-78^{\circ} 41^{\prime} \mathrm{E}$; $3524 \mathrm{~m}$ amsl) until the germination experiments were initiated. All the experiments were conducted at Indian Institute of Technology, Amingaon, Guwahati, Assam.

\section{In vitro seed germination}

Freshly harvested seeds (2-3 weeks, 3-5 $\mathrm{mm}$ in size) were surface disinfected by treating with Tween20 (HiMedia Laboratories Pvt. Ltd, India) for $20 \mathrm{~min}$ followed by incubation in $0.5 \%$ fungicide (Bevastin, India) for $20 \mathrm{~min}$ and finally washed with sterile distilled water for 4-5 times. Finally, the seeds were surface sterilized in $1.2 \%$ sodium hypochloride and $0.2 \%$ mercuric chloride for $20 \mathrm{~min}$ and 5 min respectively followed by $4-5$ washes with sterile distilled water. The aseptic seeds were dehydrated with $70 \%$ ethanol for 3 min as final treatment. The seeds ( 10 nos.) were placed in $150 \mathrm{ml}$ glass bottle containing $50 \mathrm{ml}$ of sterilized MS (Murashige and Skoog 1962) nutrient medium of different salt strength $(1 / 4,1 / 2$, and full) supplemented with $3 \%$ sucrose and $2 \%$ activated charcoal and incubated in dark for 3 days followed by transferring to light condition. Seeds were also inoculated in non-nutrient medium supplemented with 3\% sucrose and $2 \%$ activated charcoal in distilled water. The medium was solidified with $0.8 \%$ extra pure agar (HiMedia Laboratories Pvt. Ltd, India) and $\mathrm{pH}$ was adjusted to 5.8 , prior to autoclaving for $15 \mathrm{~min}$ at 1.06 $\mathrm{kg} \mathrm{cm}^{-2}\left(121^{\circ} \mathrm{C}\right)$. Seeds inoculated in media bottles were incubated at $25 \pm 2 \mathrm{C}$ under $12 \mathrm{~h}$ photoperiod with a PPFD of $40.5 \mu$ moles $\mathrm{m}^{-2} \mathrm{~s}^{-1}$ provided by cool white fluorescent lamps. The experiments were repeated thrice with fifty replicates per experiment. Statistical analysis was done by Analysis of variance (ANOVA) and means compared using Tukey's test $(p=0.05)$ (Origin 7.0 NORTHAMPTON, MA, USA). Observation was made on the percentage of seed germination after two weeks of culture.

\section{Determination of seed moisture content, viability and storability}

The dried pulps were completely removed and moisture content of fresh intact seeds was determined by drying seeds in the oven at $102^{\circ} \mathrm{C}$ for $48 \mathrm{~h}$ (Fabre and Dereuddre 1990). The percentage of moisture content was expressed on fresh weight (FW) basis using the formula

Moisture content $(\%)=($ Fresh weight - Dry weight $) /$ Fresh weight $\times 100$ 
Moisture content was also determined for $4^{\circ} \mathrm{C}$ and RT stored seeds after 6 month using above method. Similarly, moisture content of 1 year old seeds kept under the climatic condition of Laddakh was determined at Indian Institute of Technology, Guwahati. The experiment was repeated thrice with 50 replicates per experiment.

Seed viability was tested using $1 \%$ solution of TTC (2, 3, 5 triphenyl tetrazolium chloride, Sigma) with $\mathrm{pH}$ adjusted at 6.5. Around 25 dry seeds (6 month at $4^{\circ} \mathrm{C}$ and RT stored at Guwahati, Assam, India and 1 year old seeds at Ladakh, J\&K, India) were soaked in $1 \%$ aqueous solution of TTC for $24 \mathrm{~h}$ and kept in dark at room temperature. Seeds were bisected longitudinally and examined visually to determine viability percentage. Seeds with a red-stained embryo were considered to be viable. Storability of seeds was determined by analysing the percentage of seed germination for 6 month and 1 year old stored seeds in their pre-optimized (competent in vitro medium showing highest seed germination) medium. The experiments were repeated thrice with fifty replicates (50 seeds) per experiment. Statistical analysis was done by Analysis of variance (ANOVA) and means compared using Tukey's test $(p=0.05)$ (Origin 7.0 NORTHAMPTON, MA, USA). Observation was made on the percentage of seed germination after two weeks of culture.

\section{In vivo seed germination in glass house}

To study in vivo seed germination, sand and soil was ground to fine particles and mixed with vermicompost (Krishi Jigyas, Guwahati) at different ratios. Similarly, soilrite (a mixture of perlite, Irish peat moss and vermiculite) alone, purchased from Keltech Energies Pvt. Ltd, Bangalore was used according to manufacture instructions. Around $50(3-5 \mathrm{~mm})$ seeds were kept for germination in four different pots $(20 \times 20 \mathrm{~cm})$ comprising only soilrite and different mixtures of sand, soil and vermicompost at 1:1:2, 1:1:1 and 2:1:1 ratios respectively. The $\mathrm{pH}$ of these mixtures was determined using $\mathrm{pH}$ meter (Sartorious India Pvt. Ltd). The seeded pots were regularly sprinkled with water every alternate day for maintaining optimum humidity (70-80\% RH) under $12 \mathrm{~h}$ photoperiod with a photosynthetic photon flux density (PPFD) of $40.5 \mu$ moles $\mathrm{m}^{-2} \mathrm{~s}^{-1}$ and constant temperature of $22 \pm 2^{\circ} \mathrm{C}$ inside glass house. Experiments were conducted with 50 replicates and repeated thrice. Statistical analysis was done by Analysis of variance (ANOVA) and means compared using Tukey's test $(\mathrm{p}=0.05)$ (Origin 7.0 NORTHAMPTON, MA, USA). Observation was made on the percentage of seed germination after 50 days.

\section{Acclimatization and seedling establishment}

About 2 months-old in vitro raised seedlings (5-8 $\mathrm{cm}$ ) were removed from culture vessels and washed with water to remove the adhering agar. These were then potted in cups containing the optimized seedling establishing substratum. The cups were covered with perforated polybags and sprinkled with water alternately at two days interval for the initial two weeks, and acclimatized at $22 \pm 2^{\circ} \mathrm{C}$ and $50-60 \% \mathrm{RH}$ under glass-house conditions. Seedlings $(3-5 \mathrm{~cm})$ were transferred to bigger pots $(30 \times 30 \mathrm{~cm})$ containing various mixtures of surface black soil and bottom porous red soil collected from hill areas of the institute. Soil mixtures were prepared with these two types of soil alone as well as with vermicompost at 5:1 ratios respectively. In addition, a mixture of red soil, black soil and vermicompost at 1:1:1 ratios were also prepared. Substratum containing soilrite alone was considered as the control. The $\mathrm{pH}$ of these mixtures was determined using $\mathrm{pH}$ meter (Sartorious India Pvt. Ltd). The seedlings were regularly sprinkled with water every fourth day for maintaining optimum humidity $(50-60 \% \mathrm{RH})$ and grown under $12 \mathrm{~h}$ photoperiod with a Photosynthetic photon flux density (PPFD) of $40.5 \mu$ moles $\mathrm{m}^{-2} \mathrm{~s}^{-1}$ at $22 \pm 2^{\circ} \mathrm{C}$ inside glass house. Observation was made on the percentage of seedling establishment, growth and mortality after 50 days. Statistical analysis was done by Analysis of variance (ANOVA) and means compared using Tukey's test $(p=0.05)$ (Origin 7.0 NORTHAMPTON, MA, USA).

\section{Ex situ reintroduction in North East India}

One month old healthy seedling $(15-20 \mathrm{~cm})$ established under glass house conditions were transferred to the natural hilly areas of Laban, Shillong, Megha-

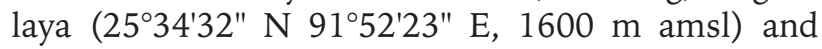

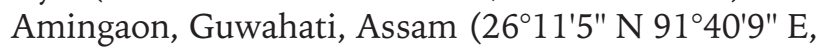
$31 \mathrm{~m}$ amsl) during the month of July 2011. Irrigation was performed initially for two weeks manually followed by natural rain water irrigation of monsoons.

\section{Results}

\section{In vitro seed germination}

For rapid mass multiplication of H. rhamnoides in vitro seeds germination was found to be very suitable. Under in vitro condition excessive secretion of polyphenols from the seeds were recorded. This permitted only $15 \%$ seed germination on non-nutrient medium lacking activated charcoal that could be further enhanced to a maximum of $36 \%$ on activated charcoal containing non nutrient medium. On addition of full MS nutrients along with activated charcoal germina- 
tion got further enhanced to an extent of $50 \%$. However, of the different strength of MS tested, a highest of $90 \%$ seed germination was recorded in $1 / 4^{\text {th }}$ MS strength supplemented with $2 \%$ activated charcoal within 10-12 days (Table 1; Fig. 1A, B). It was noted that addition of activated charcoal in the medium had a profound effect in enhancing seed germination. As compared to $1 / 4^{\text {th }}$ MS medium containing activated charcoal wherein a highest of $90 \%$ germination was recorded, germination got reduced to $40 \%$ in the same MS strength lacking activated charcoal.

Table 1. Mean seed germination percentage of $H$. rhamnoides under in vitro condition $\left(25 \pm 2^{\circ} \mathrm{C}\right)$ on different $\mathrm{MS}$ strength supplemented with activated charcoal

\begin{tabular}{ccc}
\hline MS medium strength & $\begin{array}{c}\text { Activated charcoal } \\
(2 \%)\end{array}$ & $\begin{array}{c}\text { Germination } \\
(\%)\end{array}$ \\
\hline- & + & $32.0 \pm 4.6^{\mathrm{c}}$ \\
$1 / 4$ & + & $85.33 \pm 5.8^{\mathrm{a}}$ \\
$1 / 2$ & + & $59.33 \pm 4.8^{\mathrm{b}}$ \\
Full & + & $42.66 \pm 5.9^{\mathrm{b}}$ \\
- & - & $13.33 \pm 1.7^{\mathrm{e}}$ \\
$1 / 4$ & - & $36.0 \pm 4.1^{\mathrm{c}}$ \\
$1 / 2$ & - & $27.33 \pm 4.6^{\mathrm{cd}}$ \\
Full & - & $23.33 \pm 4.0^{\mathrm{d}}$ \\
\hline
\end{tabular}

Values are mean \pm SEM of three experiments with fifty replicates/experiment.

Values followed by same letter are not significantly different according to ANOVA.

$(-)$ represents non MS medium containing only water solidified with $0.8 \%$ agar.

$(\mathrm{P}=0.05)$ and Tukey's test.

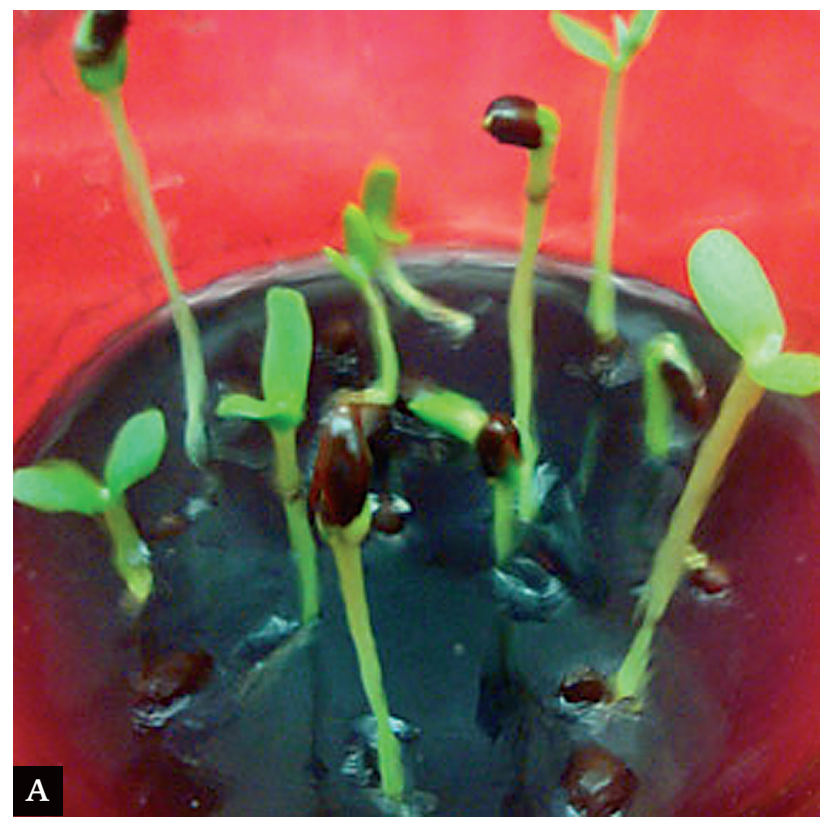

\section{Determination of seed moisture content, viability and storability}

In the present study, moisture and polyphenol content of seeds were found to be key factors for regulating higher seed germination competency and viability of $H$. rhamnoides. Seeds collected immediately from ripened fruits ( $7^{\text {th }}$ days) had an initial moisture content of $28.79 \%$. About $91 \%$ of the seeds were found to be significantly viable at this moisture level as revealed by TTC test. These viable seeds could also germinate significantly to a highest of $90 \%$ when kept under the pre-optimized in vitro medium. However, there was sharp decline in moisture content of seeds after prolonged storage ( 6 months) inside container at room temperature $\left(27 \pm 7^{\circ} \mathrm{C}\right)$ and refrigerator at $4^{\circ} \mathrm{C}$. The difference in storage condition affected the shelf life of seeds as revealed from their viability test which gradually reduced under prolonged storage. Seeds stored at $4^{\circ} \mathrm{C}$ refrigeration recorded a minimum of $79 \%$ viability with decline in moisture level to $8.33 \%$. Out of the $79 \%$ viable seeds, only $63 \%$ could germinate successfully in their optimized germination medium (Table 2). On the contrary, 6 month old seeds stored in Assam condition at RT inside container became entirely non-viable with a sharp fall in moisture level to a minimum of $3.72 \%$. Probably such low moisture content in seeds resulted into their mortality (Table 2). Morphological observation of the water imbibed de-coated 6 month old seeds also showed noticeable changes that occurred during different storage conditions. The cotyledons of seeds stored at room temperature $\left(27 \pm 7^{\circ} \mathrm{C}\right)$ turned brownish after 6 months whereas $4^{\circ} \mathrm{C}$ seeds remained whit-

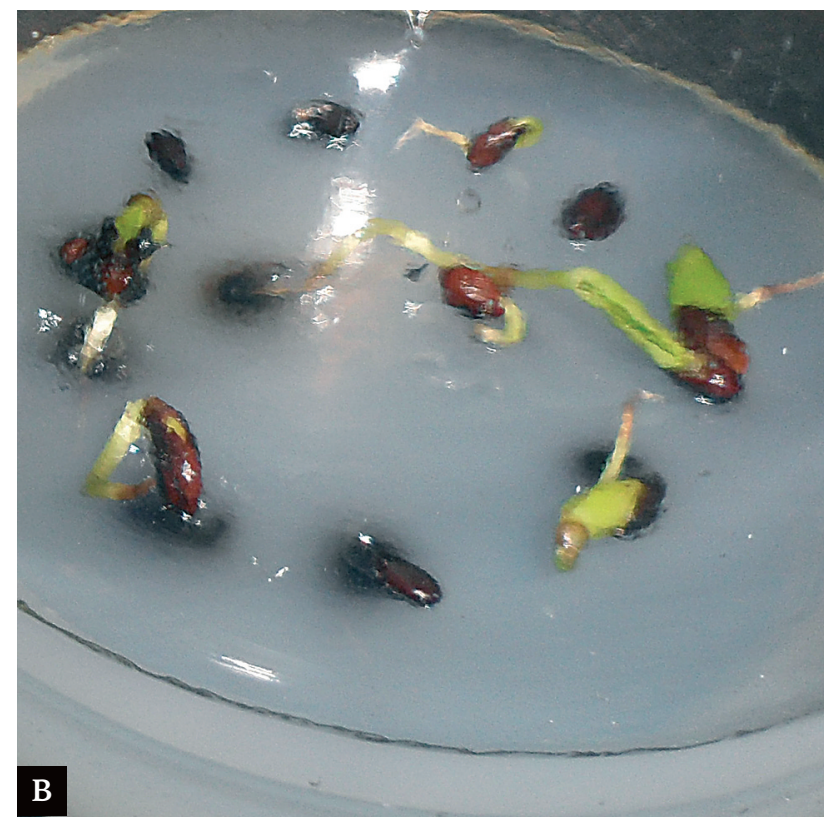

Fig. 1 A. In vitro seed germination of $H$. rhamnoides in $1 / 4^{\text {th }}$ MS medium supplemented with and B. without activated charcoal within 15 days 
ish-creamy in appearance even after its storage for 6 months. During storage at room temperature there was excessive secretion of polyphenols in the seeds leading to browning and non-viability of seeds (Fig. 2A, B). However, the phenolic secretion was comparatively lesser at $4^{\circ} \mathrm{C}$ leading to its higher viability even after 6 month of storage at Guwahati, Assam. Due to low temperature of Ladakh through-out the year, chances of polyphenol secretion in the seeds was comparatively lesser that permitted storage even for a year with around $85 \%$ seed viability and $77 \%$ germinability (Table 2; Fig. 2C, D). However, as the seeds were exposed to warmer temperature of Guwahati, Assam two phenomenal changes occurred within the seeds that reduced seed viability and germination. Firstly, there was steady fall in moisture level during storage at RT and secondly visual analysis
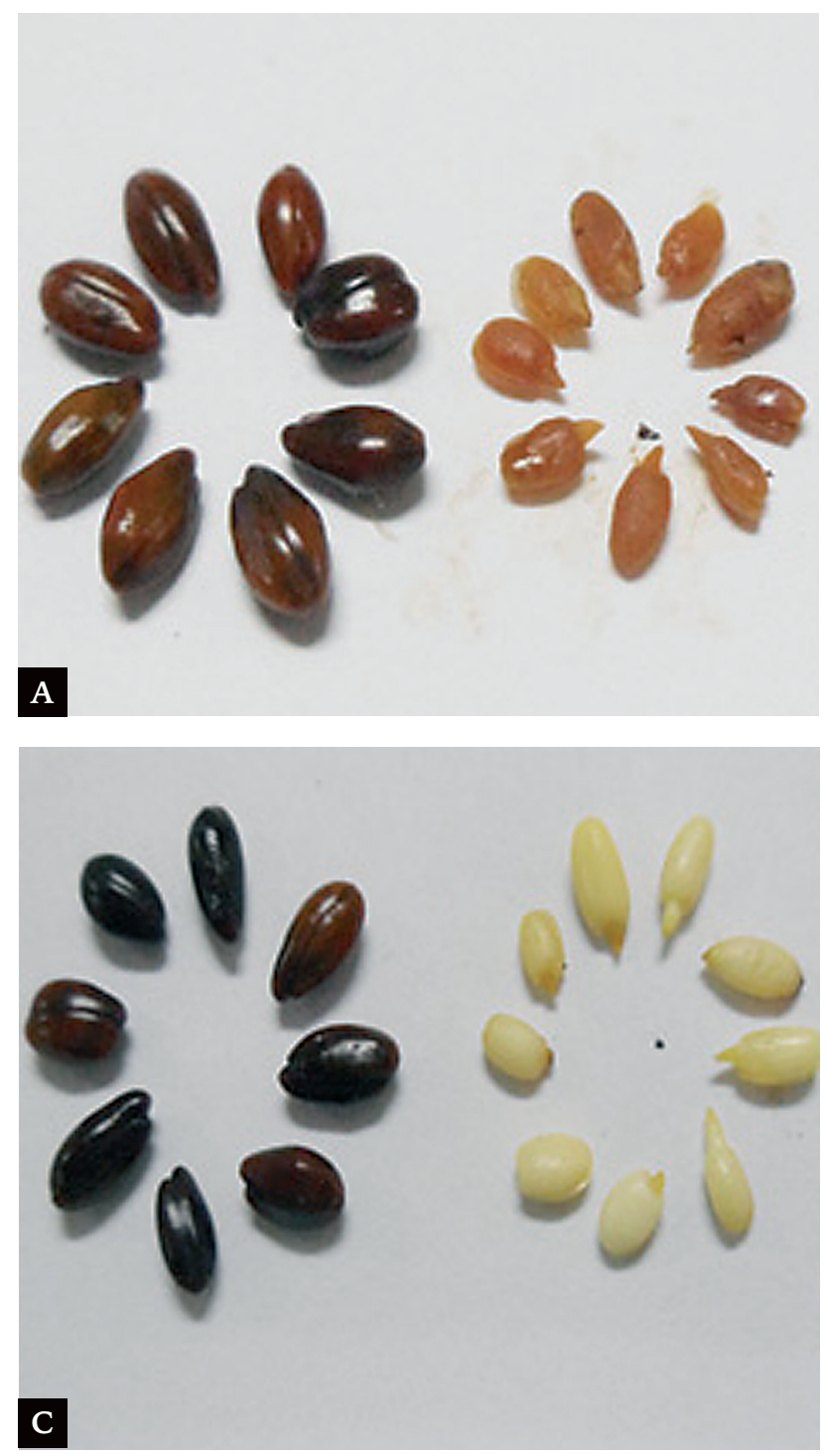

Table 2. Mean seed viability (1\% TTC) and in vitro germination percentage of $H$. rhamnoides on optimized medium kept under different storage conditions with initial $29.49 \%$ moisture content

\begin{tabular}{lccc}
\hline \multicolumn{1}{c}{ Storage condition } & $\begin{array}{c}\text { Moisture } \\
\text { Content } \%\end{array}$ & $\begin{array}{c}\text { Viability } \\
\%\end{array}$ & $\begin{array}{c}\text { Germination } \\
\%\end{array}$ \\
\hline 7 days RT & $29.49 \pm 0.41^{\mathrm{a}}$ & $89.3 \pm 2.3^{\text {ad }}$ & $85.33 \pm 5.8^{\mathrm{a}}$ \\
6 month $\left(4^{\circ} \mathrm{C}\right)$ & $9.64 \pm 0.77^{\mathrm{b}}$ & $77.0 \pm 2.0^{\mathrm{bd}}$ & $63.63 \pm 3.2^{\mathrm{bc}}$ \\
6 month (RT) & $3.72 \pm 0.26^{\mathrm{c}}$ & $0.0 \pm 0.0^{\mathrm{c}}$ & $0.0 \pm 0.0^{\mathrm{d}}$ \\
1 year RT* (Laddakh) & $5.38 \pm 0.57^{\mathrm{c}}$ & $83.6 \pm 2.6^{\mathrm{d}}$ & $76.66 \pm 1.2^{\mathrm{c}}$ \\
September 2010- & & & \\
September 2011 & & & \\
\hline
\end{tabular}

Values are mean \pm SEM of three experiments with fifty replicates/experiment; Values followed by same letter are not significantly different according to ANOVA $(\mathrm{P}=0.05)$ and Tukey's test. RT (Room temperature Guwahati $\left(27 \pm 7^{\circ} \mathrm{C}\right)$ : RT* (Room Temperature Laddakh $\left(-30\right.$ to $\left.+30^{\circ} \mathrm{C}\right)$.
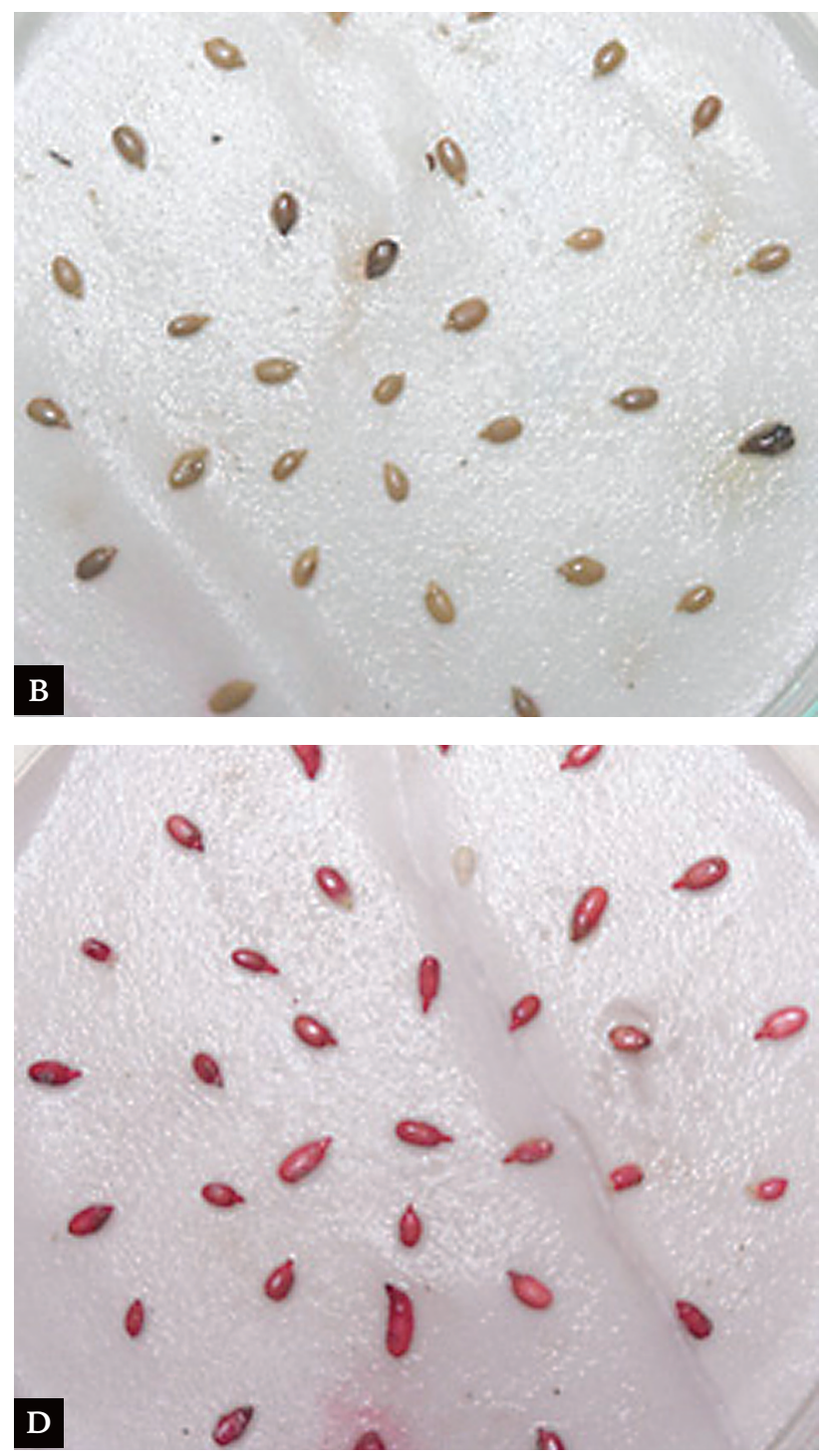

Fig. 2. A. Polyphenol secretion in 6 month old RT stored seeds of H. rhamnoides at Guwahati; B. Non-viable seeds of $H$. rhamnoides as revealed by $1 \%$ TTC test after 6 month storage at RT in Guwahati; C. Intact seeds of H. rhamnoides without polyphenol secretion after 1 year RT storage at Laddakh; D. Viable seeds of $H$. rhamnoides as revealed by $1 \%$ TTC test after 1 year RT storage at Laddakh 
revealed excessive secretion of polyphenols from the seed cotyledons due to increased temperature leading to browning and death of the embryo.

\section{In vivo seed germination in glass house}

As compared to other substrates, fresh seeds of $H$. rhamnoides showed maximum germination in soilrite under in vivo glass house condition at $22 \pm 2^{\circ} \mathrm{C}$. A maximum of $73 \%$ seed germination was recorded in soilrite within 15 days with $100 \%$ survivability which is significantly higher as compared to other substrates (Table 3; Fig 3. A, B). On the other hand, a

Table 3. Mean seed germination percentage of $H$. rhaminoides under in vivo glass house condition $\left(22 \pm 2^{\circ} \mathrm{C}\right)$ on various substratums

\begin{tabular}{lccc}
\hline Soil substratum & $\begin{array}{c}\text { Seed } \\
\text { Germination } \\
(\%)\end{array}$ & $\begin{array}{c}\text { Seedling } \\
\text { Mortality } \\
(\%)\end{array}$ & $\begin{array}{c}\text { Seedling } \\
\text { Establishment } \\
(\%)\end{array}$ \\
\hline Soilrite & $70.66 \pm 2.9^{\mathrm{a}}$ & 0.0 & $100 \pm 0.0^{\mathrm{a}}$ \\
$\begin{array}{l}\text { Sand: Soil: } \\
\begin{array}{l}\text { Vermicompost } \\
(1: 1: 2)\end{array}\end{array}$ & $48.0 \pm 4.6^{\mathrm{c}}$ & $29.43 \pm 2.4^{\mathrm{a}}$ & $70.57 \pm 2.4^{\mathrm{c}}$ \\
$\begin{array}{l}\text { Sand: Soil: } \\
\begin{array}{l}\text { Vermicompost } \\
(1: 1: 1)\end{array}\end{array}$ & $57.33 \pm 1.7^{\mathrm{b}}$ & $11.79 \pm 3.4^{\mathrm{b}}$ & $88.21 \pm 3.4^{\mathrm{bc}}$ \\
$\begin{array}{l}\text { Sand: Soil: } \\
\begin{array}{l}\text { Vermicompost } \\
(2: 1: 1)\end{array}\end{array}$ & $39.33 \pm 3.5^{\mathrm{d}}$ & $6.61 \pm 1.05^{\mathrm{b}}$ & $93.39 \pm 1.0^{\mathrm{ab}}$ \\
\hline
\end{tabular}

Values are mean \pm SEM of three experiments with fifty replicates/experiment.

Values followed by same letter are not significantly different according to ANOVA.

$(\mathrm{P}=0.05)$ and Tukey's test.

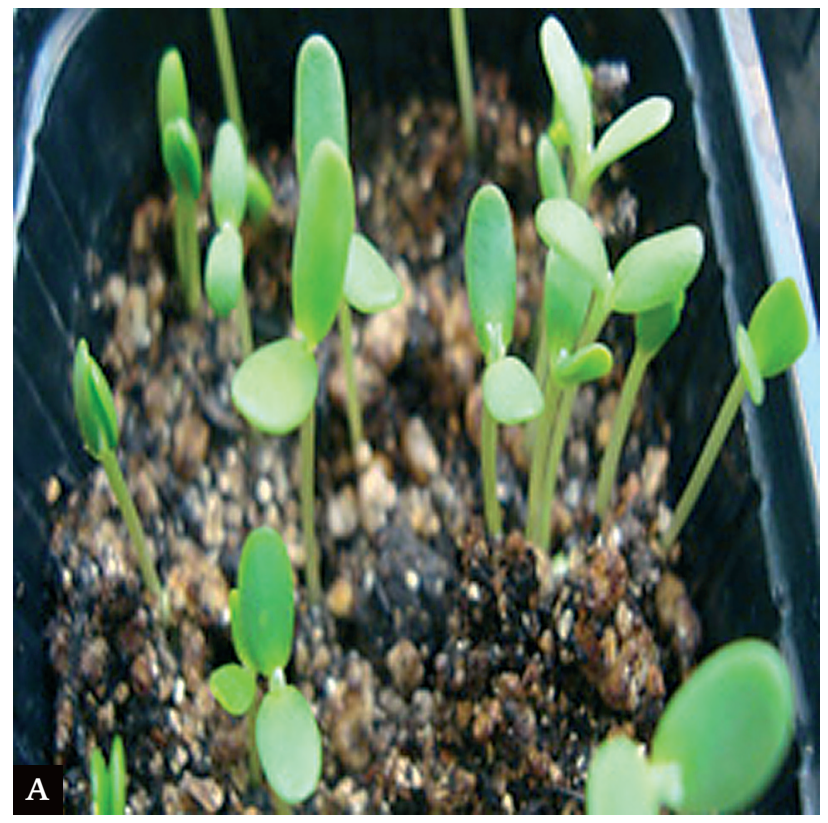

maximum of only $57.33 \%$ seed germination was recorded in readily available low cost mixture of sand, soil and vermicompost mixture at equal ratios and could be an alternative for soilrite for reducing cost.

\section{Acclimatization and seedling establishment}

The growth and the development of seedlings was better in almost all the substratum viz. humus enriched surface black soil, bottom porous red soil, bottom porous red soil mixed with vermicompost and soilrite (Table 4). More than $90 \%$ seedlings established well within one month on these entire substratum which is statistically non-significant. However the survivability of seedlings was significantly lower in rocky sandy soil with nearly $37 \%$ mortality. Seedlings attained a maximum height of $18 \mathrm{~cm}$ in bottom porous red soil and vermicompost mixture at 5:1 ratio which is significantly higher than other substratum.

\section{Ex situ reintroduction in North East India}

Survivability of seedlings of $H$. rhamnoides was greatly reduced during their acclimatization to the climatic condition of Guwahati and Shillong of North East India. Only 20\% seedlings survived in hilly areas of Laban, Shillong whereas only $45 \%$ seedlings survived at Amingaon, Guwahati within two months of their transfer. The plants suffered initial loss during their acclimatization in newly introduced locations due to biotic and as abiotic factors. Severe wilting of plants was recorded immediately after their introduction under warm $\left(30-36^{\circ} \mathrm{C}\right)$ climatic condition of July

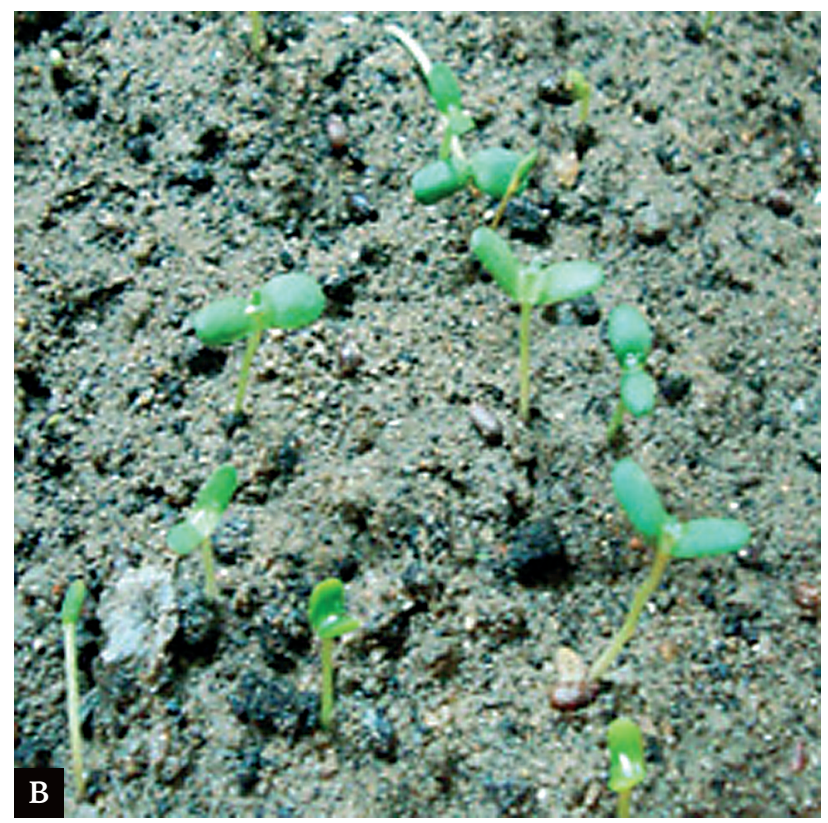

Fig. 3. A. In vivo seed germination of $H$. rhamnoides in soilrite after 15 days, B. In vivo seed germination of $H$. rhamnoides in sand: soil: vermicompost $(2: 1: 1)$ after 15 days 
Table 4. Establishment and growth of H. rhamnoides seedling in different substratum under glass house condition $\left(22 \pm 2^{\circ} \mathrm{C}\right)$

\begin{tabular}{|c|c|c|c|}
\hline $\begin{array}{l}\text { Composition } \\
\text { of Substratum }\end{array}$ & $\begin{array}{c}\text { Seedling } \\
\text { Establishment } \\
\%\end{array}$ & $\begin{array}{c}\text { Mortality } \\
\%\end{array}$ & $\begin{array}{l}\text { Shoot length } \\
\mathrm{cm}\end{array}$ \\
\hline Soilrite $(\mathrm{pH}: 6.5)$ & $98.66 \pm 0.66^{a}$ & $1.34 \pm 0.66^{\mathrm{a}}$ & $9.02 \pm 0.84^{\mathrm{a}}$ \\
\hline $\begin{array}{l}\text { Surface black soil } \\
\text { rich in humus } \\
(\mathrm{pH}: 6.5)\end{array}$ & $94.0 \pm 1.2^{\mathrm{a}}$ & $4.0 \pm 1.2^{\mathrm{a}}$ & $15.6 \pm 1.4^{\mathrm{b}}$ \\
\hline $\begin{array}{l}\text { Bottom porous } \\
\text { red soil ( } \mathrm{pH}: 6.4)\end{array}$ & $94.0 \pm 1.2^{\mathrm{a}}$ & $4.0 \pm 1.2^{\mathrm{a}}$ & $13.8 \pm 3.2^{\mathrm{ab}}$ \\
\hline $\begin{array}{l}\text { Bottom porous } \\
\text { red soil }+ \\
\text { vermicompost } \\
(5: 1)(\mathrm{pH}: 6.8)\end{array}$ & $99.3 \pm 0.66^{a}$ & $0.7 \pm 0.66^{a}$ & $17.5 \pm 1.3^{\mathrm{cb}}$ \\
\hline $\begin{array}{l}\text { Surface black soil } \\
\text { rich in humus + } \\
\text { vermicompost } \\
(5: 1)(\mathrm{pH}: 6.6)\end{array}$ & $83.3 \pm 1.7^{\mathrm{b}}$ & $16.7 \pm 1.7^{b}$ & $11.6 \pm 0.80^{a}$ \\
\hline $\begin{array}{l}\text { Rocky sandy Soil } \\
(\mathrm{pH}: 6.0)\end{array}$ & $63.3 \pm 1.7^{c}$ & $36.7 \pm 1.7^{c}$ & $6.6 \pm 1.05$ \\
\hline
\end{tabular}

Values are mean \pm SEM of three experiments with fifty replicates/experiment; Values followed by same letter are not significantly different according to ANOVA; $(\mathrm{P}=0.05)$ and Tukey's test.

- August at Guwahati, India. Pest like the cut worms was also responsible for reducing the numbers of the seedlings at Guwahati. Although temperature at Shillong $\left(17-23^{\circ} \mathrm{C}\right)$ was optimum during July-August, roots of the seedlings rotted severely due to excessive rainfall resulting into reduced survivability. Sprouting of new buds from the newly acclimatized seedlings was observed during October-November. Appropriate time for acclimatization is late winter (March-April) as observed from the healthy growth of seedlings during these seasons. Further trials must be carried out at other parts of North East India for successful massive introduction of this plant.

\section{Discussions}

Breeders need genes of plant resources and their combinations for development of new varieties. Therefore, at present more than $80 \%$ of plant genetic resources in the world are conserved as seeds in genebanks (Luan 2001). The conservation of seeds in gene banks allows ready availability of seeds for future utilization. The seeds maintained in genebanks should keep their germination capacity and genetic integrity. Therefore, the present study on seed characteristics of $H$. rhamnoides becomes very vital for its conservation and sustainable breeding. Study of seed germination in this species is very crucial since it shows epigeal germination that is considered to be evolutionarily more primitive than hypogeal germination. Thus, seed germination of this species could be enhanced only under optimized nutrient condition.
Although there are some reports of seed dormancy in H. rhamnoides, freshly collected seeds from Ladakh, India show vigorous germination under in vitro and in vivo conditions. However, low moisture content and secretion of polyphenols from the seeds reduced germination efficiency in short-term stored seeds. Numerous polyphenolic compounds have been reported in the berries of H. rhamnoides. Salicylic acid is the predominant phenolic acid besides protocatechuic, coumaric, cinnamic and ferulic acids which are also present at higher quantities in seeds (Zadernowski et al. 2005). Inhibition by ferulic acid and coumarin on lettuce seed germination were reported earlier (Williams and Hoagland 1982; Li et al. 1993; Yamamoto and Fujii 1997). Similarly, many workers have reported inhibitory effect of ferulic acid on cucumber seed germination and seedling growth (Blum and Rebbeck 1989; Booker et al. 1992; Lehman et al. 1994). These compounds act by disrupting the microtubule formation thereby preventing cell division and elongation. However, in the present study, the germination was significantly enhanced under in vitro condition containing optimum concentration of MS salts supplemented with activated charcoal. The presence of ammonium nitrate in MS medium may explain the high germination rate because $\mathrm{NH}_{4}^{+}$is readily assimilated during the initial stages of development and greatly influences growth and differentiation (Raghavan and Torrey 1964; Kramer and Kozlowski 1979). The high germination and strong further development in MS medium could be attributed to the fact that MS medium is also especially rich in both macro and micro nutrients. Germination was progressively suppressed at higher MS strength signifying the inhibitory action of the major salts at high concentration for this species (Atia et al. 2006; Bairu et al. 2009). This effect could partly be attributed to the role minerals play as osmotica. Since any germination process is preceded by imbibitions, anything that affects this process is likely to affect germination. The effect of ions like chloride, sodium, and magnesium on seed germination and plant growth is well established (Hardegree and Emmerich 1990). For instance, sodium chloride caused a significant delay and inhibition (at higher concentration) on ex vitro germination of Pteroceltis tatarinowii seeds by regulating water potential and reducing the availability of water to the germinating seed (Fang et al. 2006). According to Yam et al. (1989), the nutritional requirements of germinating seeds vary due to their physiological state and this may be species specific. MS salts at reduced concentration (1/2 and $1 / 4$ strength) have also been reported to promote better seed germination in orchids such as Dendrobium tosaense and Anoectochilus formosanus (Shiau et al. 2002; Lo et al. 2004) and medicinal herb Aconitum heterophyllum (Srivastava et al. 2011). It was noted that excessive secretion of poly- 
phenols in medium lacking activated charcoal drastically withheld seed germination. However, addition of activated charcoal in the MS medium had profound effect in adsorbing the polyphenols secreted out from the seeds that favoured enhancement of in vitro seed germination. Positive effect of activated charcoal on seed germination and morphogenesis may be due to one side surface imbibitions of inhibitor compounds in medium which minimizes toxic metabolism and exudation of phenolic compounds (Wang and Huang 1976; Thomas 2008). Similarly, positive effects of activated charcoal on seed and embryo germination of Fraxinus excelsior and Taxus baccata (Mojarabi et al. 2011; Tafreshi et al. 2011) as well as several orchid species (Moraes et al. 2005; Pacek-Bieniek 2010) has been recently reported. Under natural in vivo conditions, propagation becomes difficult as a result of various germination obstacles in Hippophae sp. seeds (Li and Schroeder 2003; Busing and Slabaugh 2008; Airi et al. 2009; Frochot et al. 2009). These obstacles are mainly because of hard seed coat or embryo dormancy that could be overcome by various chemical and mechanical treatments (Landis et al. 1996). In the present in vivo germination study, it was found that fresh seeds germinate vigorously in soilrite at $22 \pm 2^{\circ} \mathrm{C}$ under glass house condition. This is in accordance with the seed germination of $H$. rhamnoides from Poland wherein nearly $100 \%$ seed germination was recorded in sand and peat (1:1 pH 5.5-6.5) substrate at higher temperature $20-30^{\circ} \mathrm{C}$ (Tylkowski 2010). Unlike other substratums, soilrite (a mixture of perlite, Irish peat moss and vermiculite) constitutes optimum balanced source of macro and micro nutrients with better porosity and water sieving capability to maintain optimum moisture level that permits profuse seed germination. The porosity of soilrite also perhaps helps in sinking the excessive polyphenols secreted out during seed germination of $H$. rhamnoides. This is not permissible in other substratum including semi-solid agar medium where accumulation of polyphenols nearby the seeds prevents the emergence of plumule. Unlike other substratum, higher porosity also allows the better penetration of roots in soilrite promoting $100 \%$ seedling establishment in this study. Low seed germination on other substratum which consists mainly of sand, soil and vermicompost mixtures might be due to high nutrient composition and high water retention resulting into decay of seeds before germination. Recently, it has been reported that vermicompost preparations exhibits inhibitory effect on seed germination and early seedling development in certain vegetable crops. This could be due to the inhibitory effects of both humic and phenolic (gallic acid and chlorogenic acid) substances present in vermicompost (Ievinsh 2011). Similarly, low seed germination was reported earlier when trials were conducted directly in nursery soil for $H$. rhamnoides which recommends sowing of seeds in the glass house (or plastic tunnel) on sand and peat substrate (Tylkowski 2010). It was found that the efficacy of germination falls gradually with prolonged storage of seeds at warmer climatic condition. Present findings suggest using of fresh seeds instead of stored ones to obtain better results while working with $H$. rhamnoides outside its natural habitat.

\section{Conclusion}

This is a first report on in vitro and in vivo seed germination of $H$. rhamnoides under controlled temperature and humidity conditions of laboratory and glass house. From the present study it is clear that freshly harvested seeds of $H$. rhamnoides can be efficiently germinated under optimized in vitro conditions. However, seeds lose its viability on storage at warmer room temperature conditions and must be kept under low temperature for retaining higher viability for prolong period. Under natural climatic condition of Ladakh where temperature recedes below $0^{\circ} \mathrm{C}$, seeds remain viable for prolonged period. However, room temperature storage at other place is highly detrimental and must be avoided completely. The study has been conducted outside its natural climatic condition and becomes highly imperative for disseminating information on the use of $H$. rhamnoides seeds for research and breeding programmes as the condition of its storage has been well established. As literature reveals the growth of Hippophae species could occur even at diverse temperature conditions, the present investigation to introduce seedlings at cold region of Shillong, Meghalaya and also at warmer condition of Guwahati, Assam, India becomes very useful in understanding the actual acclimatization behaviour of seedlings at these two extreme climatic conditions. Reintroduction of the seedlings at the present locations is not so appealing due to several factors. However, it is felt that trials at other colder parts of North East India such as Arunanchal Pradesh and Sikkim would reveal appreciable results in future. Although introduction through cuttings is faster as compared to seedling establishment, seed derived plantlets would allow dissemination of diverse germplasm at the introduced site and is more exigent for conservation and breeders concern.

\section{Acknowledgements}

Financial support received from the Department of Biotechnology, Government of India vide grant no. $\mathrm{R} \& \mathrm{D} / 07 / \mathrm{BT} / \mathrm{P} /$ (RA)/SSB/01/2010 is gratefully acknowledged. 


\section{References}

Airi S., Bhatt I.D., Bhatt A., Rawal R.S., Dhar U. 2009. Variations in seed germination of Hippophae salicifolia with different pre-soaking treatments. Journal of Forestry Research 20: 27-30.

Akkermans A.D.L., Roelofsen W., Blom J., Hussdanell K., Harkink R. 1983. Utilization of carbon and nitrogen compounds of Frankia in synthetic media and in root nodules of Alnus glutinosa, Hippophae rhamnoides and Datisca cannabina. Canadian Journal of Botany 61: 2793-2800.

Ali A., Kaul V. 2011. Seabuckthorn: A valuable resource of the cold desert (Ladakh). ENVIS Bulletin: Himalayan Ecology 19: 1-3.

Atia A., Debez A., Rabhi M., Athar H., Abdelly C. 2006. Alleviation of salt-induced seed dormancy in the perennial halophyte Crithmum Maritimum. (Apiaceae). Pakistan Journal of Botany 38: 1367-1372.

Bairu M.W., Kulkarni M.G., Street R.A., Mulaudzi R.B., Staden J.V. 2009. Studies on seed germination, seedling growth, and in vitro shoot induction of Aloe ferox Mill., a Commercially Important Species. Hortscience 44: 751-756.

Pacek-Bieniek A., Dyduch-Siemińska M., Rudaś M. 2010. Influence of activated charcoal on seed germination and seedling development by the asymbiotic method in Zygostates grandiflora (Lindl.) Mansf. (Orchidaceae). Folia Horticulturae 22: $45-50$.

Blum U., Rebbeck J. 1989. Inhibition and recovery of cucumber roots given multiple treatments of ferulic acid in nutrient culture. Journal of Chemical Ecology 15: 917-928.

Busing R.T., Slabaugh P.E. 2008. Hippophae rhamnoides L. Common Sea buckthorn. The Woody Plant Seed Manual. In: Agriculture Hand Book 727. Karrfalt F.T., Bonner R.P. (eds.). USDA Forest Service, USA. pp. 588-590.

Booker F.L., Blum U., Fiscus E.L. 1992. Short-term effects of ferulic acid on ion uptake andwater relations in cucumber seedlings. Journal of Experimental Botany 43: 649-655.

Fabre J., Dereuddre J. 1990. Encapsulation-dehydration: New approaches to cryopreservation of Solanum shoot tips. CryoLetters 11: 413-426.

Frochot H., Balandier P., Sourisseau A. 2009. Seed Dormancy and Consequences for Direct Tree Seeding. In: Forest Vegetation Management towards Environmental Sustainability from the Final COST E47. Bentsen N.S (eds.). Vejle, Forest and Landscape Working Papers 35: 43-45.

Hardegree S.P., Emmerich W.E. 1990. Partitioning water potential and specific salt effects on seed germination of four grasses. Annals of Botany 66: 587-595.
Hendry G.A.F., Grime J.P. 1993. Methods in comparative plant ecology. A laboratory manual, Chapman and Hall, London.

Ievinsh G. 2011. Vermicompost treatment differentially affects seed germination, seedling growth and physiological status of vegetable crop species. Plant Growth Regulators 65: 169-181.

Kalia R.K., Singh R., Rai M.K., Gyan., Mishra P., Singh S.R., Dhawan AK. 2011. Biotechnological interventions in Sea buckthorn (Hippophae L.): current status and future prospects. Trees 25: 559-575.

Kanayama Y., Kato K., Stobdan T., Galitsyn G.G., Kochetov A.V., Kanahama K. 2012. Research progress on the medicinal and nutritional properties of sea buckthorn (Hippophae rhamnoides). Journal of Horticultural Science \& Biotechnology 87: 203-210.

Korekar G., Stobdan T., Chaurasia O.P., Singh S.B. 2011. Phenolic content and antioxidant capacity of various solvent extracts from seabuckthorn (Hippophae rhamnoides L.) fruit pulp, seeds, leaves and stem bark. Acta Alimentaria 40: 449-458.

Kramer P.J., Kozlowski T. 1979. Physiology of woody plants. Academic Press. New York.

Lehman M.E., Blum, U., Gerig T.M. 1994. Simultaneous effects of ferulic and pocoumaric acids on cucumber leaf expansion in split-root experiments. Journal of Chemical Ecology 20: 1773-1782.

Leme J. 1976. Osnovi biogeografii (Biogeography basis). Progress, Moscow.

Lisenkov A.F., Ekimov I.V. and Atamanov R.S. 1969. Some issues of bio-ecology of natural wilderness of sea-buckthorn in Tuva. In: Proceedings of the Tuva State Agricultural Experimental Station, pp. 292-302.

Li H.H., Inove M., Nishimura H., Mizutani J. and Tsuzuki E. 1993. Interactions of trans-cinnamic acid, its related phenolic allelochemicals, and abscisic acid in seedling growth and seed germination of lettuce. Journal of Chemical Ecol 19: 1175-1787.

Li T.S.C., Schroeder W.R. 2003. Sea Buckthorn (Hippophae rhamnoides L.): Production and Utilization. In: Propagation. Li T.S.C., Beveridge T.H.J. (eds.). NRC Research Press, Ottawa, Ontario, pp. 27-35.

Lo S.F., Nalawade S.M., Kuo C.L., Chen C.L., Tsay H.S. 2004. Asymbiotic germination of immature seeds, plantlet development and ex vitro establishment of plants of Dendrobium tosaense Makino - a medicinally important orchid. In Vitro Cellular and Developmental Biology Plant 40: 528-535.

Luan H.Y. 2001. In vitro conservation and cryopreservation of plant genetic resource. In: Establish- 
ment and management of field genebank. Saad M.S., Rao V.R. (eds.). International Plant Genetic Resource Institute, Malaysia, pp. 54-58.

Lu R. 1992. Sea buckthorn - a multipurpose plant species for fragile mountains. In: ICIMOD Occasional Paper (20). Kathmandu, Nepal, pp. 62-65.

Mamo N., Mihretu M., Fekadu M., Tigabu M., Teketay D. 2006. Variation in seed and germination characteristics among Juneperus procera populations in Ethiopia. Forest Ecology and Management 225: 320-327.

Mojarabi M., Nasr S.M.H., Jalilvand H., Kooch Y. 2011. Effect of activated charcoal, growth supplements and storage on removing dormancy, germination indices and vigour of Ash (Fraxinus excelsior L.) Annals of Biological Research 2: 203-212.

Moraes L., Faria R.T., Cuquel F.L. 2005. Activated charcoal for in vitro propagation of Brazilian orchids. Acta Horticulturae 683: 383-390.

Murashige T. and Skoog F. 1962. A revised medium for rapid growth and bioassays with tobacco tissue culture. Plant Physiology 15: 473-497.

Naithani H.B. 2004. Hippophae Linn. (Seabuckthorn) in India: A review. The Indian Forester 130: 1045-1056.

Raghavan V., Torrey J.G.1964. Inorganic nitrogen nutrition of the seedlings of the orchid Cattleya. American Journal of Botany 51: 264-274.

Raina S. N., Jain S., Sehgal D., Kumar A., Dar T. H., Bhat V., Pandey V., Vaishnavi S., Bhargav A., Singh V., Rani V., Tandon R., Tewari M., Mahmoudi A. 2012. Diversity and relationships of multipurpose seabuckthorn (HippophaeL.) germplasm from the Indian Himalayas as assessed by AFLP and SAMPL markers. Genetic Resource and Crop Evolution 59: 1033-1053.

Sankhyan H.P., Sehgal R.N., Bhrot N.P. 2005. Standardization of presowing treatments for different Seabuckthorn species in cold deserts of Himachal Pradesh. Indian Forester 131: 931-938.

Fang SZ., Li G.Y. S., Fu XX. 2006. Effects of $\mathrm{NaCl}$ stress on seed germination, leaf gas exchange and seedling growth of Pteroceltis tatarinowii. Journal of Forest Research 17: 185-188.

Shiau Y.J., Sagare A.P., Chen U.C., Yang S.R., Tsay H.S. 2002. Conservation of Anoectochilus formosanus Hayata by artificial cross-pollination and in vitro culture of seeds. Botanical Bulletin of Academic Sinica 43:123-130.
Srivastava N., Sharma V., Dobriyal A.K., Kamal B., Gupta S., Jadon V.S. 2011. Influence of pre-sowing treatment on in vitro seed germination of Ativisha (Aconitum heterophyllum). of Uttarakhand. Biotechnology 10: 215-219.

Stobdan T., Angchuk D., Singh S.B. 2008. Seabuckthorn: An emerging storehouse for researchers in India. Current Science 94: 1236-1237.

Stobdan T., Chaurasia O.P., Korekar G., Mundra S., Ali Z., Yadav A., Singh S.B. 2010. Attributes of seabuckthorn (Hippophae rhamnoides L.) to meet nutritional requirements in high altitude. Defence Science Journal 60: 226-230.

S.A.H., M., M.R., M.K. 2011. Rapid germination and development of Taxus baccata $\mathrm{L}$. by in vitro embryo culture and hydroponic growth of seedlings. 47: $561-568$.

Thomas T.D. 2008. The role of activated charcoal in plant tissue culture. Biotechnology Advances 26: 618-631.

Tylkowski T. 2010. Seed germination and seedling emergence in Hippophae rhamnoides L. Dendrobiology 63: 53-58.

Wang P.J., Huang L.C.1976. Beneficial effects of activated charcoal on plant tissue and organ cultures. In Vitro Cellular \& Developmental Biology Plant 12: 260-262.

Williams R.D. and Hoagland R.E. 1982. The effects of naturally occurring phenolic compounds on seed germination. Weed Science 30: 206-212.

Yam T.W., Arditti J., Weatherhead M.A. 1989. The use of darkening agents in seed germination and tissue culture media for orchids: a review. Journal of the Orchid Society of India 3: 35-39.

Yamamoto Y. and Fujii Y. 1997. Exudation of allelopathic compound from plant roots of sweet vernal grass (Anthoxanthum odoratum). Journal of Weed Science and Technology 42: 31-35.

Yao Y. 1994. Genetic diversity, evolution and domestication in sea buckthorn. PhD dissertation, Helsinki University, Finland.

Zadernowski R., Naczkb M., Czaplicki S., Rubinskienec M. and Szalkiewicz M. 2005. Composition of phenolic acids in Sea Buckthorn (Hippophae rhamnoides L.) berries. Journal of the American Oil Chemist's Society 82: 175-179.

Zhang J. 2000. buckthorn Sea development to promote soil and water conservation and ecological development in the "Three Norths" area of China. Hippophae. Icrtsnewsletter 13(1). 